\title{
Impact of rituximab on patient-reported outcomes in patients with rheumatoid arthritis from the US Corrona Registry
}

\author{
Leslie R. Harrold ${ }^{1,2}$ • Ani John ${ }^{3}$. Jennie Best ${ }^{3}$ - Steve Zlotnick ${ }^{3}$. Chitra Karki ${ }^{2}$ • \\ YouFu Li ${ }^{1}$. Jeffrey D. Greenberg ${ }^{4}$ • Joel M. Kremer ${ }^{5}$
}

Received: 13 June 2017 / Accepted: 25 June 2017 /Published online: 17 July 2017

(C) The Author(s) 2017. This article is an open access publication

\begin{abstract}
To evaluate the impact of rituximab on patientreported outcomes (PROs) in a US-based observational cohort of patients with rheumatoid arthritis (RA). Patients with active RA, prior exposure to $\geq 1$ tumor necrosis factor inhibitor (TNFi) and who newly initiated rituximab were identified. Changes in PROs were assessed 1 year after rituximab initiation. PRO measures included Clinical Disease Activity Index (CDAI); patient global disease activity, pain and fatigue (visual analog score; 0-100); morning stiffness (hours); modified Health Assessment Questionnaire (mHAQ; 0-3); and EuroQoL EQ-5D. Of the 667 patients who newly initiated rituximab, baseline PRO and clinical measures indicated that patients were substantially impacted by their RA disease and quality of life; $54 \%$ of patients had high disease activity. One year after rituximab initiation, 49.0, 47.1, 49.8, and 23.2\% of patients reported clinically meaningful improvements in patient global, pain, fatigue, and $\mathrm{mHAQ}$, respectively. Morning stiffness and EuroQol EQ-5D domains improved in 48 and $19-32 \%$ of patients, respectively. These real-world registry data demonstrated that patients with long-standing, refractory
\end{abstract}

Electronic supplementary material The online version of this article (doi:10.1007/s10067-017-3742-2) contains supplementary material, which is available to authorized users.

Leslie R. Harrold

leslie.harrold@umassmed.edu

University of Massachusetts Medical School, Worcester, MA, USA

2 Corrona, LLC, Southborough, MA, USA

3 Genentech, Inc., South San Francisco, CA, USA

4 New York University School of Medicine, New York, NY, USA

5 Albany Medical College and the Center for Rheumatology, Albany, NY, USA
RA experienced improvements in PROs 1 year after initiating rituximab.

Keywords Biologics · Patient-reported outcomes · Rheumatoid arthritis · Rituximab

\section{Introduction}

Patients with rheumatoid arthritis (RA) often experience reduced health-related quality of life (HRQOL), including disability and RA-related comorbidities [1,2]. The goals of treatment in RA are to achieve low disease activity (LDA) or remission and to improve HRQOL.

Patient-reported outcomes (PROs) include HRQOL indices, such as the ability to perform day-to-day tasks, emotional health, and the degree of pain and discomfort. PROs are increasingly being recognized as important measures in determining response to therapy in patients with RA [3-5].

Rituximab is a monoclonal antibody that targets and depletes $\mathrm{CD} 20^{+} \mathrm{B}$ cells and, in combination with methotrexate, is approved for the treatment of RA in patients who have had an inadequate response to $\geq 1$ tumor necrosis factor inhibitor (TNFi). Limited data exist on the effect of rituximab on PROs in real-world clinical settings. This study examined the impact of rituximab on PROs in a US observational cohort of patients with RA.

\section{Methods}

\section{Study setting}

The Corrona RA Registry is an independent, prospective, observational cohort of patients with RA [6, 7]. 
Patients are recruited from 169 private and academic practice sites across 40 states in the USA, with 656 participating rheumatologists. As of June 20, 2016, data on 43,099 patients with RA have been collected. The protocol was approved by the New England institutional review board (IRB; \#120160610) and the local IRBs of participating academic sites. Registration number: NCT01402661.

\section{Study analysis population}

Adult patients with RA who initiated rituximab for the first time within Corrona from March 2006 to September 2015 were identified. Eligible patients had available PRO measurements at baseline (around the time of rituximab initiation) and 1 year (9-15 months) after rituximab initiation. All patients had previously received $\geq 1$ TNFi and had low, moderate, or high disease activity based on Clinical Disease Activity Index (CDAI), defined as CDAI $>2.8$.

\section{Assessments and outcomes}

CDAI was assessed at 1 year and evaluated by the median change from baseline and by the proportion of patients achieving LDA/remission (CDAI $\leq 10)$. PROs were assessed at 1 year and included the median change from baseline and the proportion of patients reporting minimum clinically important differences (MCIDs; defined as improvement of $\geq 10$ ) in patient global assessment of disease, pain, and fatigue $(0-100$ on a visual analog scale) [8]; improvement in morning stiffness (duration in hours); proportion of patients achieving a clinically meaningful improvement in modified Health Assessment Questionnaire (mHAQ), defined as a decrease of $>0.25$ from baseline in the mHAQ score [9]; and improvement in the EuroQol EQ-5D overall health status index, which records patient-reported HRQOL across five domains (walking, self-care, usual activities, pain/discomfort, and anxiety/depression). EuroQol EQ$5 \mathrm{D}$ results are examined using a summary index $(0-1)$ or by individual evaluation of each domain [10]. Improvement in EQ-5D domains was defined as the proportion of patients with any improvement or resolution of impairment among patients who reported impairment at baseline.

PROs and CDAI were evaluated for both the overall cohort and in patient populations stratified by number of prior TNFis ( 1 or $\geq 2$ prior TNFis). For patients with $\geq 2$ visits within the time frame for the 12-month visit, the visit closest to 12 months was used.

\section{Statistical analysis}

Comparisons between the 1 and $\geq 2$ prior TNFi groups were performed using $\chi^{2}, t$, or nonparametric equality-of-medians tests, as appropriate. Responses for the outcome measures were available for $>95 \%$ of patients during the time when the variables were part of the data collection process; patients with missing data were excluded from outcome analyses.

\section{Results}

\section{Patient demographics and baseline PROs}

A total of 667 patients were included (Supplemental Fig. 1); $284(42.6 \%)$ had received 1 prior TNFi, and $383(57.4 \%)$ had received $\geq 2$ prior TNFis. Most patients were female (78.7\%), and the overall median age was 59 (interquartile range [IQR], 50-66) years (Table 1). The median duration of RA was 13 (IQR, 7-21) years, and 53.8\% of patients had high disease activity $(\mathrm{CDAI}>22)$ at baseline. Significantly higher proportions of patients with $\geq 2$ prior TNFis had received $\geq 1$ nonTNFi biologic (53.8 vs $39.1 \%$ ) and were in high disease activity (CDAI $>22 ; 58.2$ vs $47.9 \%)$ than patients with 1 prior TNFi.

Patients were substantially impacted by their RA at baseline. Overall, baseline median (IQR) scores for patient global assessment, pain, and fatigue were 40 (25-60), 60 (31-75), and $65(40-80) \mathrm{mm}$, respectively (Table 1$)$. The baseline median mHAQ score was 0.6 (IQR, $0.3-1$ ), and patients reported a median of 1 (IQR, 0.5-2) hour of morning stiffness. Most patients reported at least some problems in the EQ-5D categories of walking (75.7\%), usual activities $(81.1 \%)$, and pain/ discomfort $(95.8 \%)$. Almost one-half of all patients reported at least some problems in self-care (48.6\%) and anxiety/ depression (49.0\%). Baseline PRO scores were mostly similar between patients who had received 1 or $\geq 2$ prior TNFis, with the exception of fatigue and morning stiffness.

\section{Rituximab persistency}

Overall, $78.9 \%$ of patients persisted on rituximab through 1 year, whereas $21.1 \%$ switched to another biologic before 1 year. Among all patients, $63.3 \%$ received rituximab retreatment and did not switch to another biologic, and $15.6 \%$ did not receive rituximab retreatment but also did not switch to another biologic (Supplemental Table 1).

\section{Improvement in CDAI and PROs 1 year after rituximab initiation}

The median improvement in CDAI from baseline to 1 year was 8 (IQR, 17.8); results were similar between patients with 
Table 1 Baseline patient demographics, clinical characteristics, disease activity, and PRO measures

\begin{tabular}{|c|c|c|c|c|}
\hline & $\begin{array}{l}\text { Total } \\
N=667\end{array}$ & $\begin{array}{l}1 \text { Prior TNFi } \\
n=284\end{array}$ & $\begin{array}{l}\geq 2 \text { Prior TNFis } \\
n=383\end{array}$ & $P$ value $^{\mathrm{a}}$ \\
\hline \multicolumn{5}{|l|}{ Demographics and clinical characteristics } \\
\hline Age, median (IQR), years & $59(50-66)$ & $60(52-69)$ & $58(49-65)$ & 0.013 \\
\hline Female, $n(\%)$ & $525(78.7)$ & $223(78.5)$ & $302(78.9)$ & 0.918 \\
\hline White, $n(\%)$ & $582(87.3)$ & $241(84.9)$ & $341(89)$ & 0.110 \\
\hline Duration of RA, median (IQR), years $[n]$ & $\begin{array}{l}13(7-21) \\
{[664]}\end{array}$ & $\begin{array}{l}11(6-22) \\
{[281]}\end{array}$ & $\begin{array}{l}14(7-27) \\
{[383]}\end{array}$ & 0.071 \\
\hline History of cardiovascular disease, $n(\%)$ & $42(6.3)$ & $17(6.0)$ & $25(6.5)$ & 0.776 \\
\hline History of diabetes, $n(\%)$ & $61(9.1)$ & $26(9.2)$ & $35(9.1)$ & 0.994 \\
\hline History of hyperlipidemia, $n / N(\%)$ & $22 / 317(6.9)$ & $10 / 129(7.8)$ & $12 / 188(6.4)$ & 0.638 \\
\hline RF seropositive, $n / N(\%)$ & 290/395 (73.4) & $123 / 164(75.0)$ & $167 / 231(72.3)$ & 0.549 \\
\hline No. of prior nonbiologic DMARDs, median (IQR) & $1(0-2)$ & $1(0-2)$ & $2(1-3)$ & $<0.001$ \\
\hline \multicolumn{5}{|l|}{ No. of prior non-TNFi biologics, $\%$} \\
\hline $\begin{array}{l}0 \\
1\end{array}$ & $\begin{array}{l}350(52.5) \\
228(34.2)\end{array}$ & $\begin{array}{l}173(60.9) \\
82(28.9)\end{array}$ & $\begin{array}{l}177(46.2) \\
146(38.1)\end{array}$ & \multirow[t]{2}{*}{0.001} \\
\hline$\geq 2$ & $89(13.3)$ & $29(10.2)$ & $60(15.7)$ & \\
\hline \multicolumn{5}{|l|}{ CDAI score, $n(\%)$} \\
\hline $\begin{array}{l}\text { Low }(>2.8 \text { and } \leq 10) \\
\text { Moderate }(>10 \text { and } \leq 22)\end{array}$ & $\begin{array}{l}81(12.1) \\
227(34.0)\end{array}$ & $\begin{array}{l}38(13.4) \\
110(38.7)\end{array}$ & $\begin{array}{l}43(11.2) \\
117(30.5)\end{array}$ & \multirow[t]{2}{*}{0.029} \\
\hline $\operatorname{High}(>22)$ & $359(53.8)$ & $136(47.9)$ & $223(58.2)$ & \\
\hline \multicolumn{5}{|l|}{ HRQOL measures, median (IQR) $[n]$} \\
\hline Patient global assessment $(0-100)$ & $\begin{array}{l}40(25-60) \\
{[667]}\end{array}$ & $\begin{array}{l}40(24.5-55) \\
{[284]}\end{array}$ & $\begin{array}{l}40(25-60) \\
{[383]}\end{array}$ & 0.302 \\
\hline Patient pain $(0-100)$ & $\begin{array}{l}60(31-75) \\
{[667]}\end{array}$ & $\begin{array}{l}50(25-75) \\
{[284]}\end{array}$ & $\begin{array}{l}60(36-75) \\
{[383]}\end{array}$ & 0.084 \\
\hline Patient fatigue $(0-100)$ & $\begin{array}{l}65(40-80) \\
{[295]}\end{array}$ & $\begin{array}{l}55(26-75) \\
{[123]}\end{array}$ & $\begin{array}{l}70(48.5-85) \\
{[172]}\end{array}$ & 0.014 \\
\hline mHAQ score $(0-3)$ & $\begin{array}{l}0.6(0.3-1) \\
{[660]}\end{array}$ & $\begin{array}{l}0.6(0.3-1) \\
{[283]}\end{array}$ & $\begin{array}{l}0.8(0.3-1) \\
{[377]}\end{array}$ & 0.094 \\
\hline Morning stiffness, hours & $\begin{array}{l}1(0.5-2) \\
{[650]}\end{array}$ & $\begin{array}{l}1(0.5-2) \\
{[277]}\end{array}$ & $\begin{array}{l}1.5(0.5-2.8) \\
{[373]}\end{array}$ & 0.019 \\
\hline EQ-5D (0-1) & $\begin{array}{l}0.7(0.6-0.8) \\
{[274]}\end{array}$ & $\begin{array}{l}0.7(0.6-0.8) \\
{[114]}\end{array}$ & $\begin{array}{l}0.7(0.6-0.8) \\
{[160]}\end{array}$ & 0.228 \\
\hline
\end{tabular}

$C D A I$ clinical disease activity index, $D M A R D$ disease-modifying antirheumatic drug, $H R Q O L$ health-related quality of life, $I Q R$ interquartile range, $m H A Q$ modified Health Assessment Questionnaire, $P R O$, patient-reported outcome, $R A$ rheumatoid arthritis, $R F$ rheumatoid factor, $T N F i$ tumor necrosis factor inhibitor

${ }^{\text {a }}$ The $P$ value represents the comparison between patients who received 1 prior TNFi vs those who received $\geq 2$ prior TNFis

1 or $\geq 2$ prior TNFis. Overall, $30.4 \%$ of patients achieved CDAI LDA/remission $(\mathrm{CDAI} \leq 10)$ at 1 year. A significantly higher proportion of patients with 1 prior TNFi achieved CDAI LDA/remission than patients with $\geq 2$ prior TNFis (37.7 vs $25.1 \%$, respectively; $P<0.001$ ).

Improvement from baseline was observed in all PRO measures at 1 year. The overall median (IQR) scores of patient global assessment, pain, and fatigue improved by 7 (35), 7 (30), and 9 (25) mm, respectively. The proportions of patients with improvements $\geq$ MCID in patient global assessment, pain, and fatigue were 49.0, 47.1, and $49.8 \%$, respectively (Fig. 1a). Clinically meaningful improvement in mHAQ was reported in $23.2 \%$ of patients (Fig. 1b). Almost one-half of all patients (48.3\%) reported some improvement in morning stiffness, with $19.8 \%$ reporting a reduction in the duration of morning stiffness of $>60 \mathrm{~min}$ (Fig. 1c).

Patients also experienced improvement in all EQ-5D domains at 1 year; among patients who reported problems at baseline, $19 \%$ of patients reported at least some improvement in walking, $30 \%$ in self-care, $24 \%$ in usual activities, $23 \%$ in pain/discomfort, and $32 \%$ in anxiety/depression (Fig. 2). Among patients who reported problems at baseline, $19 \%$ of patients reported no problems in walking, $27 \%$ in self-care, $18 \%$ in usual activities, $11 \%$ in pain/discomfort, and $32 \%$ in anxiety/depression. Similar improvements were observed between patients who received 1 prior TNFi and those who received $\geq 2$ prior TNFis. 
A

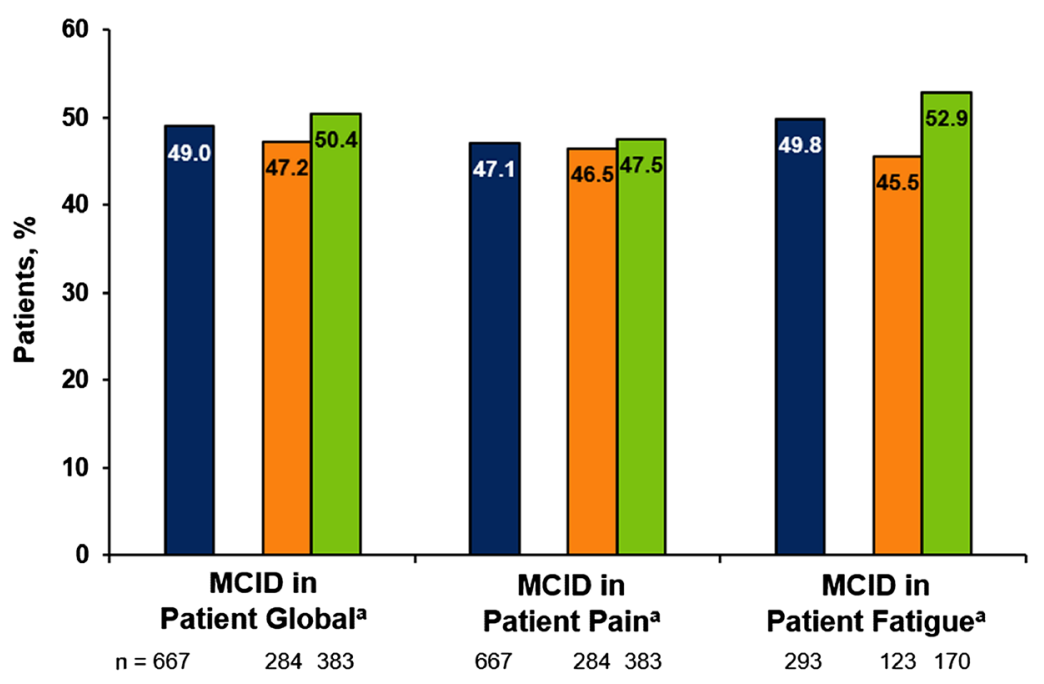

C

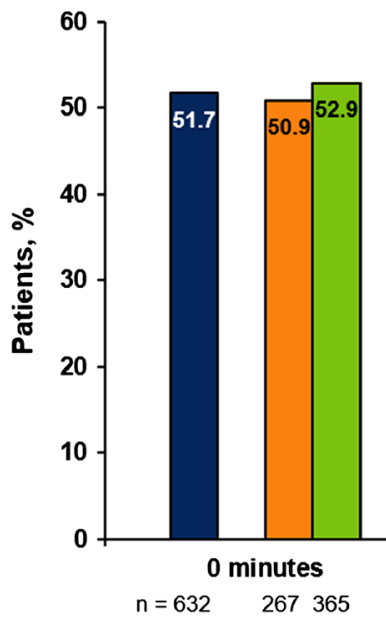

Fig. 1 Improvement in PROs (a), mHAQ (b), and duration of morning stiffness (c) 1 year after initiation of rituximab, overall and by prior TNFi use. $M C I D$ minimum clinically important difference, $m H A Q$ modified Health Assessment Questionnaire, $P R O$ patient-reported outcome, $T N F i$

\section{B}

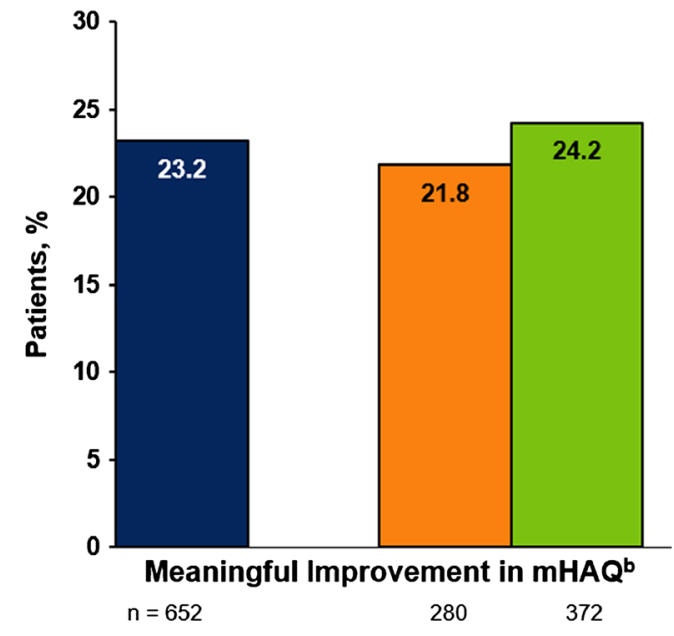

Fig. 2 Improvement in EQ-5D categories at 1 year among rituximab initiators, overall and by prior TNFi use. TNFi tumor necrosis factor inhibitor. $a$ Percentage of patients reporting improvement among patients who reported difficulty in each measure at baseline. $b$ Improvement in the EQ-5D domains was defined as either patients improving from moderate to no disability or those with severe disability improving to moderate or no disability

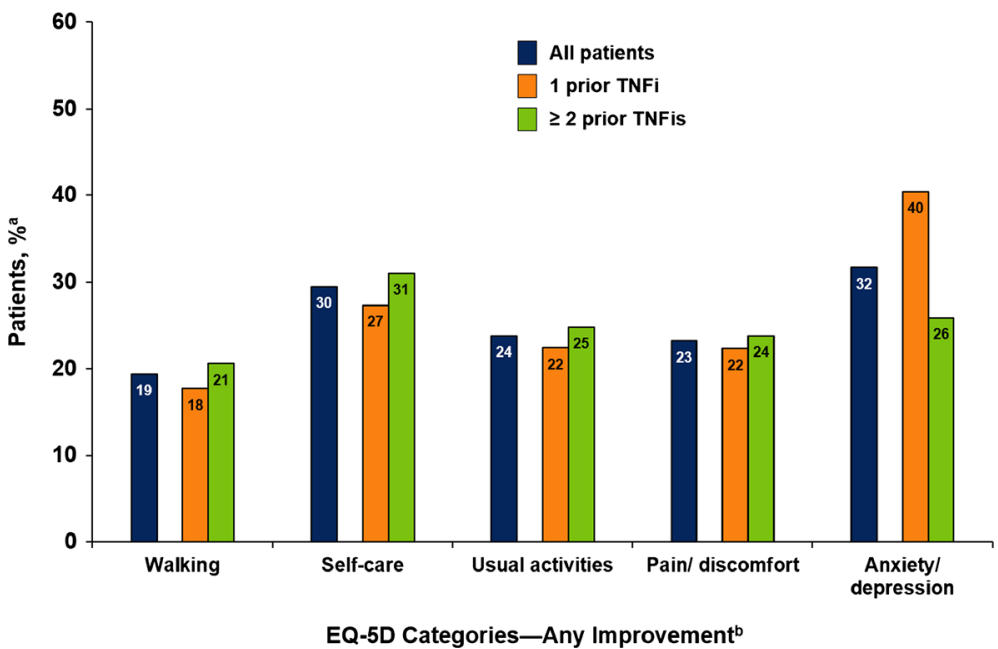




\section{Discussion}

In this real-world cohort of patients with long-standing, refractory RA with active disease and prior TNFi exposure, improvements were reported in all PROs 1 year after initiation of rituximab. The overall median duration of RA was 13 years; whereas all patients had prior TNFi exposure, almost one-half $(47.5 \%)$ had also received $\geq 2$ prior nonTNFi biologics. At baseline, $88 \%$ of patients had moderate or high disease activity based on CDAI, and patients were substantially impacted by their RA: most patients reported problems with walking, usual activities, and pain/discomfort, and almost one-half reported problems with self-care and anxiety/depression. One year after initiation of rituximab, $30 \%$ of patients achieved LDA/ remission $(\mathrm{CDAI} \leq 10)$, and $49.0,47.1$, and $49.8 \%$ of patients achieved MCIDs in patient global, pain, and fatigue, respectively. Among patients who had reported problems at baseline, 11-32\% reported no problems in walking, selfcare, usual activities, pain/discomfort, and anxiety/ depression at 1 year.

Clinical trials have also reported improvements in PROs among patients with comparable disease duration and prior use of TNFis; however, these studies reported different PRO measures, including HAQ - disability index, Functional Assessment of Chronic Illness Therapy-Fatigue, and Short Form 36, 6 months after initiation of rituximab, limiting the ability to directly compare our results with clinical trial results $[11,12]$. Real-world data on PROs in rituximab-treated patients with RA are limited. A recent open-label study of rituximab in patients with long-standing RA showed that improvement in PROs occurred early after initiation of rituximab, plateaued at 12 weeks, and persisted through 24 weeks [13]. Although our study did not include PRO measures at time points of $<1$ year, our findings suggest that the improvement in PROs after rituximab initiation extends through 1 year.

This analysis is among the first to describe patient realworld experience with rituximab treatment 1 year after initiation. Patients in this observational cohort were treated and followed consistent with routine care rather than based on a mandated treatment protocol or visit schedule. Most patients $(\approx 80 \%)$ persisted with rituximab through 1 year. However, because the follow-up period for this analysis was limited to 1 year, the long-term effect of rituximab, with or without retreatment, on PROs could not be ascertained.

In conclusion, these results suggest that treatment with rituximab can improve HRQOL in addition to controlling or improving underlying disease in patients with long-standing RA previously treated with TNFis.

Acknowledgements Support for third-party writing assistance, furnished by Ellen Mercado, $\mathrm{PhD}$, of Health Interactions, Inc., was provided by Genentech, Inc./F. Hoffmann-La Roche, Ltd.
Compliance with ethical standards

Funding This study was sponsored by Corrona, LLC. Corrona, LLC has been supported through contracted subscriptions in the last 2 years by AbbVie, Amgen, AstraZeneca, Bristol-Myers Squibb, Crescendo, Eli Lilly, Genentech, GSK, Horizon Pharma, Janssen, Momenta Pharmaceuticals, Novartis, Pfizer, Roche, and UCB.

Conflict of interest LRH is an employee of the University of Massachusetts Medical School and is a consultant for Bristol-Myers Squibb. AJ, JB, and SZ are employees of Genentech. CK is an employee of Corrona, LLC. YL declares no conflicts of interest. JDG is an employee and shareholder of Corrona, LLC, and a consultant for Genentech, Janssen, Novartis, Pfizer, and Eli Lilly. JMK is an employee and shareholder of Corrona, LLC, and a consultant for AbbVie, Amgen, BristolMyers Squibb, Genentech, GSK, Eli Lilly, Pfizer, Regeneron, and Sanofi.

Open Access This article is distributed under the terms of the Creative Commons Attribution 4.0 International License (http:// creativecommons.org/licenses/by/4.0/), which permits unrestricted use, distribution, and reproduction in any medium, provided you give appropriate credit to the original author(s) and the source, provide a link to the Creative Commons license, and indicate if changes were made.

\section{References}

1. Michaud K, Wolfe F (2007) Comorbidities in rheumatoid arthritis. Best Pract Res Clin Rheumatol 21:885-906. doi:10.1016/j.berh. 2007.06.002

2. Scott DL, Steer S (2007) The course of established rheumatoid arthritis. Best Pract Res Clin Rheumatol 21:943-967. doi:10. 1016/j.berh.2007.05.006

3. Deshpande PR, Rajan S, Sudeepthi BL, Abdul Nazir CP (2011) Patient-reported outcomes: a new era in clinical research. Perspect Clin Res 2:137-144. doi:10.4103/2229-3485.86879

4. Her M, Kavanaugh A (2012) Patient-reported outcomes in rheumatoid arthritis. Curr Opin Rheumatol 24:327-334. doi:10.1097/ BOR.0b013e3283521c64

5. Kalyoncu U, Dougados M, Daurès JP, Gossec L (2009) Reporting of patient-reported outcomes in recent trials in rheumatoid arthritis: a systematic literature review. Ann Rheum Dis 68:183-190. doi:10. 1136/ard.2007.084848

6. Curtis JR, Chen L, Bharat A, Delzell E, Greenberg JD, Harrold L, Kremer J, Setoguchi S, Solomon DH, Xie F, Yun H (2014) Linkage of a de-identified United States rheumatoid arthritis registry with administrative data to facilitate comparative effectiveness research. Arthritis Care Res (Hoboken) 66:1790-1798. doi:10.1002/acr. 22377

7. Kremer JM (2016) The Corrona US registry of rheumatic and autoimmune diseases. Clin Exp Rheumatol 34(5 Suppl 101):S96-S99

8. Wells G, Li T, Maxwell L, MacLean R, Tugwell P (2007) Determining the minimal clinically important differences in activity, fatigue, and sleep quality in patients with rheumatoid arthritis. J Rheumatol 34:280-289

9. Wolfe F, Pincus T (1999) Listening to the patient: a practical guide to self-report questionnaires in clinical care. Arthritis Rheum 42: 1797-1808. doi:10.1002/1529-0131(199909)42:9<1797::AIDANR2 $>3.0 . C O ; 2-Q$

10. Hurst NP, Kind P, Ruta D, Hunter M, Stubbings A (1997) Measuring health-related quality of life in rheumatoid arthritis: validity, responsiveness and reliability of EuroQol (EQ-5D). Br J Rheumatol 36:551-559 
11. Keystone E, Burmester GR, Furie R, Loveless JE, Emery P, Kremer J, Tak PP, Broder MS, Yu E, Cravets M, Magrini F, Jost F (2008) Improvement in patient-reported outcomes in a rituximab trial in patients with severe rheumatoid arthritis refractory to anti-tumor necrosis factor therapy. Arthritis Rheum 59:785-793. doi:10. 1002/art.23715

12. Mease PJ, Revicki DA, Szechinski J, Greenwald M, Kivitz A, Barile-Fabris L, Kalsi J, Eames J, Leirisalo-Repo M (2008) Improved health-related quality of life for patients with active rheumatoid arthritis receiving rituximab: results of the doseranging assessment: international clinical evaluation of rituximab in rheumatoid arthritis (DANCER) trial. J Rheumatol 35:20-30

13. Gossec L, Danré A, Combe B, Le Loët X, Tebib J, Sibilia J, Mariette X, Dougados M. (2015) Improvement in patient-reported outcomes after rituximab in rheumatoid arthritis patients: an openlabel assessment of 175 patients. Joint Bone Spine 82:451-454. doi: 0.1016/j.jbspin.2015.02.007 